\title{
DIREITOS HUMANOS E GLOBALIZAÇÃO: UNIVERSALIDADE VERSUS UNIFORMIDADE
}

\author{
Gustavo Rabay Guerra*
}

Sumário: 1. Enquadramento inicial - 2. Como o processo de globalização se desdobrou na necessidade de uma integração ética universal: contra a escatologia - 3. Os direitos humanos no mundo globalizado: sistema protetivo universal ou imposição de um modelo político hegemônico? 4. É possível (ou desejável) defender a criação de um sistema de proteção jusfundamental cooperativo? - 5. Referências.

\section{Enquadramento inicial ${ }^{1}$}

Um dos debates mais associados à crise atual de justificação/legitimação do direito e do Estado moderno consiste na identificação de uma possível articulação da globalização, em especial de seus desdobramentos interculturalistas, e o discurso de afirmação/efetivação dos direitos humanos, com toda a força lógico-legitimante a ele vinculado, no paradigma do Estado democrático de Direito.

Partindo do ideal kantiano de justiça, fundado em liberdade e igualdade transcendentes, diversos filósofos condicionam a conformação de uma sociedade global às cedências e ascendências de uma ética universal calcada na proteção cooperativa dos direitos humanos. $^{2}$

\footnotetext{
* Mestre em Direito (UFPE). Professor do UNIEURO - Centro Universitário Euro-Americano e do UniCEUB Centro Universitário de Brasília. Ex-Professor do Instituto de Ensino Superior da Paraíba (IESP), da Faculdade de Direito de Caruaru (FDC-ASCES), do Centro de Ciências Jurídicas da Universidade Federal da Paraíba (CCJUFPB) e da Universidade Estadual da Paraíba (UEPB). Advogado em Brasília-DF.

${ }^{1}$ Agradeço ao Prof. Dr. Bruno Galindo (UFRN/FDC-ASCES) pelas valiosíssimas reflexões compartilhadas a respeito de tão vasto e obliterante temário. Grato, de igual sorte, ao Prof. Dr. João Maurício Adeotato (UFPE), pela disponibilização de material para esse limitadíssimo estudo e pelas lições, tanto de teoria geral e de filosofia jurídicas, como de seriedade e zelo acadêmico, sempre presentes em minhas reflexões. Meus agradecimentos, também, ao Prof. Dr. Humberto Ávila (UFRGS) pela exortação à pesquisa madura que deve se almejar no contexto brasileiro, longe dos sabores acríticos de mera "reprodução de façanhas literárias estrangeiras". Manifesto, ainda, profunda admiração e agradecimento ao Prof. Dr. Eduardo Rabenhorst (UFPB), à conta de sua escorreita análise do problema aqui enfocado, em seu artigo intitulado "Direitos humanos e globalização contrahegemônica: notas para o debate", multicitado no presente texto e que constitui a verdadeira motivação para o enfrentamento da situação-problema.

${ }^{2}$ Cf. Joaquim Carlos Salgado. A idéia de justiça em Kant. 2. ed. Belo Horizonte, 1995; Alexandre Travessoni Gomes. Ética, direito e paz perpétua. In: Jean-Christophe Merle e Luiz Moreira (org.). Direito e Legitimidade. São Paulo: Landy, 2003, p. 298-308; Otfried Höffe. Estados Nacionais e Direitos Humanos na era da globalização. In: Jean-Christophe Merle e Luiz Moreira (org.). Direito e Legitimidade. São Paulo: Landy, 2003, p. 309-321. Para uma visão crítica do tema, cf. Carlos Santiago Nino. Ética y derechos humanos - un ensayo de fundamentación. 2. ed. Buenos Aires: Astrea, 1989, p. 129-196; Eduardo Rabenhorst. Direitos humanos e globalização contra-hegemônica: notas para o debate. In: Lyra, Rubens Pinto (org.). Direitos humanos: os
} 
Sobrejacente ao problema de um topos legitimador dos direitos humanos na ordem global, afigura-se invencivelmente complexa a estratégia de incorporação da mensagem de Kant em torno da paz perpétua, assinalada em posições filosóficas totalizantes e descuradas de uma correta compreensão da realidade das sociedades periféricas e das culturas infensas ao ideal democrático ocidental.

O presente escrito suscita uma introdutória investigação do problema, perfilando alguns argumentos filosóficos que possibilitem um debate de caráter plúrimo acerca da criação de um pacto jusfundamental global. Trata-se, em verdade, de versão atualizada de trabalho inédito que foi apresentado e obteve menção honrosa no III Concurso de Artigos Jurídicos, realizado durante o VI Simpósio Nacional de Direito Constitucional, promovido pela Academia Brasileira de Direito Constitucional nos dias 4, 5, 6 e 7 de outubro de 2004, em Curitiba-PR. Ainda assim, um texto à procura de concreto amadurecimento e propriamente lançado para suscitar esforços acadêmicos que sinalizem com uma resposta mais contextualizada para a questão posta.

\section{Como o processo de globalização se desdobrou na necessidade de uma integração ética universal: contra a escatologia}

Ao longo do século que se findou, a humanidade experimentou uma intensa transição de paradigmas, permeada por imponentes rupturas ideológicas, pela insatisfação do ser humano com sua própria condição, pelos grandes desafios de uma época em que as transformações operam-se na velocidade da fibra ótica, em que informações cruciais são transmitidas no tempo real da Informática. Um século intenso, marcado por extremos, em que o Homem, alguns anos antes de deflagrar a corrida espacial e a viragem para as novas tecnologias midiáticas, consagrou o assassínio de milhões de semelhantes, como se deu com o genocídio nazista ${ }^{3}$.

As respostas de antes se entremostram insuficientes para preencher o grande vazio despertado pela atual reformatação do saber, tomado de assalto pelas perplexidades

\footnotetext{
desafios do século XXI - uma abordagem interdisciplinar. Brasília: Brasília Jurídica, 2002, p. 17-24; e João Mauricio Adeodato. La pretensión de universalización del derecho como ambiente ético común. In: El derecho ante la globalización y el terrorismo. Valencia: Tirant lo Blanch, 2004, v.1, p. 99-108.

${ }^{3}$ Como aludido por Eric Hobsbawn. A Era dos Extremos: O Breve Século XX - 1914-1991. São Paulo: Companhia das Letras, 1995.
} 
contemporâneas, que assinalam a ocorrência de fenômenos incomensuravelmente impactantes, tais como a globalização e a integração de blocos econômicos.

Para além da mera concepção de uma interface econômica mantida por diversos atores internacionais e da possibilidade real de cingir-se distância e tempo, o processo em destaque comporta inúmeras variáveis compreensivas ${ }^{4}$. Conceitualmente, é extremamente delicado falar nesses termos. Não é todo e qualquer problema compartilhado por uma fração da chamada comunidade planetária que preenche o conceito de globalização. O fenômeno é, em si mesmo, muito mais complexo, pois pressupõe nuances culturais, econômicas e ideológicas.

Segundo André-Jean Arnaud ${ }^{5}$, é possível anotar algumas condições para se obter um discurso afinado à idéia de interação global cientificamente erigida:

a) uma mudança nos modelos de produção, que facilita as transferências de algumas atividades especificas de um país para outro;

b) o aparecimento de mercados de capitais transfronteiriços, isto é, o desenvolvimento de mercados fora do âmbito das nações;

c) a expansão das empresas multinacionais, beneficiadas por aquilo que se convencionou chamar de economia planetária;

d) o desenvolvimento de acordos comerciais entre nações que formam blocos econômicos regionais, calcadas numa integração supranacional, tal como ocorre com a União Européia, com o Mercosul e ALCA;

e) um ajuste estrutural das funções do aparelho estatal, diminuindo-se sua intervenção com processos como a privatização das empresas públicas, em que "as próprias estruturas jurídicas são afetadas e adaptadas à interação econômica";

f) a hegemonia do neoliberalismo econômico, mormente ocasionada pelo mercado privatizado, pelo livre mercado internacional, desregulação, não intervencionismo estatal, práticas, enfim, que hoje se difundem em todos os continentes;

g) uma tendência generalizada à democratização, à proteção dos direitos humanos, a um renovado interesse pelo Estado de direito;

\footnotetext{
${ }^{4}$ Cf. Octávio Tanni. Teorias da globalização. Rio de Janeiro: Civilização Brasileira, 1995; e Gilmar Antonio Bedin. O fenômeno da globalização do mundo e as possibilidades de realização da sociedade atual: é possível construir uma nova ordem mundial justa e solidária? Estudos Jurídicos. São Leopoldo: Unisinos, v. 36, n. 97, p. 5-34, 2003.

${ }^{5}$ André-Jean Arnaud. O direito entre Modernidade e Globalização: Lições de Filosofia do Dir eito e do Estado. Trad. Patrice Charles Wuillaume. Rio de Janeiro: Renovar, 1999, p. 12-14.
} 
h) o surgimento de atores supranacionais e transnacionais promovendo essa democracia e essa proteção dos direitos humanos, tais como as Organizações Nãogovernamentais (ONG's).

Como acentua Hobsbawn, a tensão existente entre globalização e a incapacidade das instituições públicas e do comportamento coletivo dos indivíduos de se acomodarem a ele constituem o ponto nevrálgico do novo século ${ }^{6}$.

O avanço da globalização é fulminado, em proporções gigantescas, por diversos conflitos, antes desconhecidos, porque foram esses mesmos ocasionados pelo próprio processo de globalização, cujos riscos aumentam em razão da complexidade ínsita ao seu delineamento ${ }^{7}$ : (i) riscos ligados à natureza (questões climáticas, desequilíbrios ecológicos e problemas ambientais em geral); (ii) riscos ligados aos progressos tecnológicos (corrida espacial, exploração da energia nuclear, telecomunicações, manipulação genética); (iii) riscos ligados à ação organizada (terrorismo, guerras étnicas, guerra nuclear etc); e (iv) riscos ligados à desorganização do "mercado" (protecionismos nacionais, especulações, tensão entre países de indústria consolidada e os subdesenvolvidos).

Ao passo em que sociedade hipercomplexa enfrenta as grandes rupturas ideológicas com o projeto filosófico da modernidade e experimenta o avanço irrefreável da ciência, o direito, porquanto, sistema normativo da conduta humana, não consegue oferecer respostas efetivas para as provocações desse período inigualável de indeterminismos.

Entrementes, à vista dos incontáveis contratempos com que os atores sociais podem se deparar na nova ordem mundializada, os grandes desafios da regulação jurídica hodierna continuam sinalizando uma antiga questão: a legitimação do Direito. Como as normas jurídicas podem apresentar fundamentação ética adequada ao grupamento social em que elas incidem? Máxime no período histórico atual - o ambiente pós-moderno ${ }^{8}$-, da descrença no poder absoluto da razão e do desprestígio do Estado, em que o "efêmero e o volátil parecem derrotar o permanente e o essencial", em que se vive a "angústia do que não pôde ser e a

\footnotetext{
${ }^{6}$ Eric Hobsbawn. A Era dos Extremos: O Breve Século XX - 1914-1991. São Paulo: Companhia das Letras, 1995, p. 24.

${ }^{7}$ André-Jean Arnaud. O direito entre Modernidade e Globalização: Lições de Filosofia do Direito e do Estado. Trad. Patrice Charles Wuillaume. Rio de Janeiro: Renovar, 1999, p. 5. Cf., ainda, a esse respeito, R. De Giorgi. Direito, Democracia e Risco: Vinculos com o Futuro. Porto Alegre: Sérgio Antonio Fabris, 1998.

${ }^{8}$ Qualidade relativa à pós-modernidade, exploração filosófica do pensador francês Jean-François Lyotard, que, em apertada síntese, consiste na tentativa de descrever o grande ceticismo e a perplexidade que se observam no modelo societal dos dias atuais. A obra referência é La Condition Post Moderne, do próprio Lyotard. Cf. a versão traduzida: Jean-François Lyotard. A Condição Pós-Moderna. Rio de Janeiro: José Olympio, 2003.
} 
perplexidade de um tempo sem verdades seguras", a suficiência do aparato jurídico é algo extremamente delicado.

O problema da legitimação continua o mesmo, no entanto, os influxos da acentuada complexidade do novo modelo societal globalizado acabam por retorcer e inviabilizar inúmeras possibilidades de se pactuar o regramento jurídico e o contexto moral no qual o mesmo se insere.

O problema desloca-se agora para o ambiente mundial transfigurado pelo próprio adventício das vertentes globais de interação social.

Aqui, impõe-se cautela indubitável: o debate sobre as vias de legitimação de uma proteção jurídica planetária como corolário da própria tendência globalizante consiste em uma preocupação com o próprio Homem e suas conseqüências. Não deve ser tratado de maneira totalizante, nem escatológica ${ }^{10}$.

Com isso, o processo em destaque não pode ser entendido sob a ótica da modernidade, tampouco baseado nas incipientes posições ideológicas acerca da uniformização dos mercados e do neoliberalismo econômico que impregnaram o fim do século passado; sua viabilidade vincula o próprio programa de sobrevivência dos seres humanos em seu atual estágio cultural (ocidental). Insuficiente pensar o irreversível processo como mero delírio ideológico ${ }^{11}$, mas, sobremaneira, como a possibilidade de se deslocar o enfoque restrito à transnacionalização do capital e operar conceitos e iniciativas que propugnem a cidadania planetária ou ética cívica transnacional, na expressão de Adela Cortina ${ }^{12}$.

\footnotetext{
${ }^{9}$ Luís Roberto Barroso. Fundamentos teóricos e filosóficos do novo direito constitucional brasileiro (Pósmodernidade, teoria crítica e pós-positivismo). Revista da Academia Brasileira de Direito Constitucional. Curitiba, a. 1, n. 1, 2001, p. 17-18.

${ }^{10}$ Como esclarece o Prof. João Maurício Adeodato, "escatologia" tem dois sentidos etimologicamente diversos: do grego skór, atós, ou seja, excremento ou caráter relativo a excremento, que obviamente não é o significado aqui; e do grego éscathos, último, isto é, uma "doutrina sobre a consumação do tempo e da história", um "tratado sobre os fins últimos do homem". João Mauricio Adeodato. Ética e Retórica - Por uma teoria da dogmática jurídica. São Paulo: Saraiva, 2002, p. 299.

${ }^{11}$ Gilmar Antonio Bedin. O fenômeno da globalização do mundo e as possibilidades de realização da sociedade atual: é possível construir uma nova ordem mundial justa e solidária? Estudos Jurídicos. São Leopoldo: Unisinos, v. 36, n. 97, 2003, p. 18.

${ }^{12}$ Adela Cortina. Ética transnacional e cidade cosmopolita. In: Jean-Christophe Merle e Luiz Moreira (org.). Direito e Legitimidade. São Paulo: Landy, 2003, p. 286s.
} 


\section{Os direitos humanos no mundo globalizado: sistema protetivo universal ou imposição de} um modelo político hegemônico?

A proposta de adequação aos impasses da nova ordem global passa pelo desafio de construção de um ambiente ético-jurídico comum ${ }^{13}$. O processo de legitimação/legitimidade do horizonte ético universal recebe os influxos das diferenças erigidas na nova ordem internacional de maneira natural.

Na ótica habermasiana, o direito moderno se amolda especialmente à integração social de sociedades econômicas que, em domínios de ação neutralizados do ponto de vista ético, dependem de decisões descentralizadas de sujeitos singulares. Assim, ressalta que esse direito retira dos indivíduos "o fardo das normas morais e as transfere para leis que garantem a compatibilidade das liberdades de ação". ${ }^{4}$

Com isso, surge um novo apelo jurídico para composição da equação dos riscos do discurso globalista.

Essa necessidade parte da constatação de um abalo à perspectiva clássica de soberania e autodeterminação de um povo, até mesmo por conta das novas funções desempenhadas pelos Estados nacionais na esfera comunitária: auxílio à formação dos blocos regionais e cooperação ética, em busca da construção de uma cidadania transnacional, cosmopolita. ${ }^{15}$

Como ressalta Höffe, a relativização da soberania dos Estados nacionais não prenuncia sua superação ${ }^{16}$. Em primeiro plano é o Estado soberano que propicia à ética do direito a governabilidade societal. Não se trata de se apregoar o desaparecimento do Estado moderno, mas reconhecer-lhe um novo estatuto, de modo a viabilizar a conciliação entre os Estados e um sistema de jurisdição internacional, para dirimir controvérsias marcantes, cujos riscos se

\footnotetext{
${ }^{13}$ Cf. João Mauricio Adeodato. La pretensión de universalización del derecho como ambiente ético común. In: El derecho ante la globalización y el terrorismo. Valencia: Tirant lo Blanch, 2004, v.1, p. 99-108.

14 Jürgen Habermas. Direito e democracia - Entre facticidade e validade. Trad. Flávio Beno Siebeneichler. Rio de Janeiro: Tempo Brasileiro, 1997, t. I, p. 114.

${ }^{15}$ Nesse sentido, cf. José Eduardo Faria. Direito e globalização econômica: introdução. In: José Eduardo Faria (org.). Direito e globalização econômica: implicações e perspectivas. São Paulo: Malheiros, 1998, p. 11, in litteris: "O denominador comum dessas rupturas é, como se vê, o esvaziamento da soberania e da autonomia dos Estados nacionais. Por um lado, o Estado já não pode mais almejar regular a sociedade civil nacional por meio de seus instrumentos jurídicos tradicionais, dada a crescente redução de seu poder de intervenção, controle, direção e indução. Por outro lado, ele é obrigado a compartilhar sua soberania com outras forças que transcendem o nível nacional. Ao promulgar suas leis, portanto, os Estados nacionais acabam sendo obrigados a levar em conta o contexto econômico-financeiro internacional, para saber o que podem regular e quais de suas normas serão efetivamente respeitadas."

${ }^{16}$ Otfried Höffe. Estados Nacionais e Direitos Humanos na era da globalização. In: Jean-Christophe Merle e Luiz Moreira (org.). Direito e Legitimidade. São Paulo: Landy, 2003, p. 311.
} 
estendem à boa parte da humanidade e, até mesmo, erigir-se um Estado de âmbito global, realizando, assim, o projeto kantiano da construção de uma federação mundial ( $\dot{A} P a z$ Perpétua) ${ }^{17}$.

Com efeito, inúmeros autores defendem a possibilidade de concreção desse ambiente ético comum para a humanidade. Um exemplo estrutural pode ser encontrado no ideário de Karl-Otto Apel e sua ética da responsabilidade: para Apel, a "ética da responsabilidade" nada mais é do que uma ética dialógica que se articula através da interação social, mediação que possibilita "as condições de existência da Comunidade ideal com a Comunidade real", empregando para isso, de forma similiar a Habermas, uma racionalidade comunicativa ${ }^{18}$.

O conteúdo das normas jurídicas, assim, estaria intrinsecamente conectado ao paradigma moral, a ser determinado com base em um discurso em que todos os atores pudessem "dar seu assentimento, na qualidade de participantes de discursos racionais" - a situação ideal. ${ }^{19}$

De regresso a Habermas, a sua insistência em idealizar um programa democrático para o Ocidente desvela não existir outro caminho a não ser a perspectiva legitimadora através da afirmação/concreção dos direitos humanos. ${ }^{20}$ Diz ele que a teoria política deu uma resposta dupla à questão, através da soberania do povo e dos direitos humanos, em que tem grande relevo e função o procedimento democrático de escolha dos programas políticos vinculantes. $^{21}$

\footnotetext{
${ }^{17}$ Gilmar Antonio Bedin. O fenômeno da globalização do mundo e as possibilidades de realização da sociedade atual: é possível construir uma nova ordem mundial justa e solidária? Estudos Jurídicos. São Leopoldo: Unisinos, v. 36, n. 97, 2003, p. 19.

${ }^{18}$ Karl-Otto Apel. Estudios Éticos. Barcelona: Editorial Alfa, 1986. p. 94s; cf. do mesmo autor: Karl-Otto Apel. Transformação da filosofia, v. 2: o a priori da comunidade de comunicação. Trad. Paulo Astor Soethe. São Paulo: Loyola, 2000; Karl-Otto Apel. Globalización y necesidad de una ética universal. In: Adela Cortina e Domingo García-Marzá. Razón pública y éticas aplicadas. Madrid: Tecnos, 2003; As bases dessa "racionalidade comunicativa" societal baseada em Kant podem ser encontradas em: Karl-Otto Apel. La ética del discurso como ética de la responsabilidad. Una transformación posmetafísica de la ética de Kant. In: Karl-Otto Apel. Teoría de la verdad y ética del discurso, Barcelona, Paidós/ICE-UAB, 1991; e Jürgen Habermas. Consciência Moral e Agir Comunicativo. Trad. Guido A. de Almeida. Rio de Janeiro: Tempo Brasileiro, 1989.

${ }^{19}$ Alexandre Travessoni Gomes. Ética, direito e paz perpétua. In: Jean-Christophe Merle e Luiz Moreira (org.). Direito e Legitimidade. São Paulo: Landy, 2003, p. 305.

${ }^{20}$ Jürgen Habermas. Sobre a legitimação baseada nos direitos humanos. Trad. Gisele Guimarães Citadino e Maria Celina Bodin de Moraes. Direito, Estado e sociedade. Rio de Janeiro: PUC-RIO, v. 9, n. 17, p. 190-208, ago-dez. 2000; Também publicado em Jürgen Habermas. Sobre a legitimação pelos direitos humanos. Trad. Claudio Molz. In: Jean-Christophe Merle e Luiz Moreira (org.). Direito e Legitimidade. São Paulo: Landy, 2003, p. 67-82

${ }^{21}$ Jürgen Habermas. Sobre a legitimação baseada nos direitos humanos. Trad. Gisele Guimarães Citadino e Maria Celina Bodin de Moraes. Direito, Estado e sociedade. Rio de Janeiro: PUC-RIO, v. 9, n. 17, ago-dez. 2000, p. 193.
} 
Rabenhorst, em luminar contributo crítico, assevera ser fácil supor que, após a promulgação da Declaração da ONU de 1948, o discurso instituidor dos direitos humanos significa o mesmo que universalizar o Direito, na perspectiva defendida por Kant em $\dot{A} P a z$ Perpétua, ou seja, com vistas à proteção e promoção de valores universais inquestionáveis. No entanto, diz ele, há um dado colateral ameaçador: este processo de universalização, "do ponto de vista histórico, sempre oscilou entre as diversas formas de utopia comunitária e a mera justificação da ideologia liberal de auto-regulamentação mercantil". ${ }^{22}$

A depor contra o ideal otimista e progressista da constituição de um ambiente éticojurídico universal, enfatiza Rabenhorst a ambivalência de sentimentos que ele sinaliza: em lugar de um sistema universal de direitos e deveres recíprocos, ocorreria, em verdade, a imposição de um modelo político hegemônico. ${ }^{23}$

Para ele, isso resulta da pertença ocidental dos direitos humanos ("eles nasceram no Ocidente e foram propagados pelo Ocidente"), que colide frontalmente com valores ínsitos a outras sociedades, não reconhecidos por boa parte dos Estados democráticos da cultura hegemônica. Afinal, trata-se de uma questão de universalidade ou uniformidade, de ordem a simplesmente se impor um alinhamento dos valores consagrados pelo Ocidente?

Rabenhorst especula, fincado no pensamento do italiano Danilo Zolo ${ }^{24}$, que o sistema protetivo internacional dos direitos humanos - notoriamente uniformizador e eurocêntrico escamoteia as reais motivações da instalação desse aparelho aparentemente utópico: a despeito de se afigurar irrealizável, esse ambiente cosmopolita deve ser entendido como indesejável, eis que o problema da legitimidade concentra-se na impossibilidade de uma composição heterogênea (e não simplesmente democrática) da comunidade internacional, em que os atores ocupam posições nitidamente $\operatorname{assimétricas~}^{25}$. Que base compreensiva e nível

\footnotetext{
${ }^{22}$ Eduardo Rabenhorst. Direitos humanos e globalização contra-hegemônica: notas para o debate. In: Lyra, Rubens Pinto (org.). Direitos humanos: os desafios do século XXI - uma abordagem interdisciplinar. Brasília: Brasília Jurídica, 2002, p. 20-21.

${ }^{23}$ Idem, p. 21.

${ }^{24}$ Cf. Danilo Zolo. Positive Tolerance: An Ethical Oxymoron. Ratio Juris. Oxford, v. 10, n. 2, p. 241-251, jun. 1997. Nesse trabalho, o autor analisa a proposta da transcendência hermenêutica da "tolerância positiva" sugerida por Apel.

${ }^{25}$ O filósofo lembra que o órgão mais importante da ONU, o Conselho de Segurança, mantém a sua estrutura original com os mesmos membros permanentes com poder de vetar qualquer decisão, o que conduz, como é fácil pressentir, uma aplicação parcial das normas de Direito Internacional. Eduardo Rabenhorst. Direitos humanos e globalização contra-hegemônica: notas para o debate. In: Lyra, Rubens Pinto (org.). Direitos humanos: os desafios do século XXI - uma abordagem interdisciplinar. Brasília: Brasília Jurídica, 2002, p. 21.
} 
participativo desempenhariam os países e organizações periféricas? E as sociedades de cultura colidente?

O próprio processo de globalização vem tendo como uma de suas vias a imposição de padrões de modernização jurídica a todos os Estados participantes, "restando a marginalização da comunidade internacional àqueles que não o fizerem". ${ }^{26}$

Como reafirma Santiago Nino, os direitos humanos mantêm vínculos inarredáveis com a consciência e dever morais de uma sociedade ${ }^{27}$; uniformizar a proteção desses direitos seria tal como reconhecer acepções morais de cunho universal, de sorte a cultivar os pressupostos básicos do ideal kantiano de justiça e liberdade, sem a depuração necessária à conta dos desafios atuais.

De mais a mais, o debate em destaque não pode prescindir a consideração da ambivalência detectada por Rabenhorst, na ótica desenvolvida por Boaventura de Sousa $\operatorname{Santos}^{28}:$ de um lado, a globalização possibilitou a criação de uma identidade planetária, que, por sua vez, realçou identidades locais, o que traduz um sentimento anti-hegemônico. O processo pode ter mesmo favorecido a implantação do regime democrático em algumas partes do mundo. Por outro lado, o desenvolvimento de uma ambiência ética universal, com um aparato governamental internacional ${ }^{29}$, pode significar exatamente o contrário, ou seja, a indiferença cultural em grau máximo, desrespeitando barreiras humanas sob a argumentação de proteção suprema dos direitos humanos.

Convém, por fim, salientar que a "globalização não parecer sugerir uma necessidade, mas uma possibilidade que não pode ser antecipadamente conhecida" e deve ser tomada em seu caráter sistêmico, como ressalta Marcelo Neves - na senda de Luhmann, de ordem a sugerir mais "possibilidades (alternativas) do que as suscetíveis de serem atualizadas"; a complexidade advém da constatação de que "as alternativas possíveis de conduta,

\footnotetext{
${ }^{26}$ João Mauricio Adeodato. Ética e Retórica - Por uma teoria da dogmática jurídica. São Paulo: Saraiva, 2002, p. 302.

${ }^{27}$ Carlos Santiago Nino. Ética y derechos humanos - un ensayo de fundamentación. 2. ed. Buenos Aires: Astrea, 1989, p. 11-48; e 129-196.

${ }^{28}$ Eduardo Rabenhorst. Direitos humanos e globalização contra-hegemônica: notas para o debate. In: Lyra, Rubens Pinto (org.). Direitos humanos: os desafios do século XXI - uma abordagem interdisciplinar. Brasília: Brasília Jurídica, 2002, p. 19.

${ }^{29}$ Tal qual a proposta por Habermas de "transformação da atual Assembléia Geral da Nações Unidas em um Parlamento mundial composto por representantes da 'sociedade civil global', escolhidos de forma democrática". Eduardo Rabenhorst. Direitos humanos e globalização contra-hegemônica: notas para o debate. In: Lyra, Rubens Pinto (org.). Direitos humanos: os desafios do século XXI - uma abordagem interdisciplinar. Brasília: Brasília Jurídica, 2002, p. 22.
} 
comunicações, relações e fatos sociais são muito maiores do que aquelas que se podem realizar efetivamente em uma situação concreta", implicando, assim, contingência dos cometimentos. ${ }^{30}$ Com efeito, complexidade e contingência resultam o aumento da necessidade de seleção - e simultaneamente de riscos -, "mas exigem mecanismos seletivos que não excluam, definitiva e absolutamente, nenhuma possibilidade". 31 A intrigante conseqüência disso é que a "redução seletiva da complexidade conduz ao aumento de complexidade, ou seja, os mecanismos seletivos destinam-se a transformar complexidade desestruturada em complexidade estruturada, sem desconhecer, portanto, a heterogeneidade de valores, interesses e discursos, assim como a pluralidade de sistemas existentes na sociedade". ${ }^{32}$

\section{4. É possível (ou desejável) defender a criação de um sistema de proteção jusfundamental cooperativo?}

Otfried Höffe, aproximando-se de uma concepção jusnaturalista de ordenação jurídica $^{33}$, propõe a determinação de princípios efetivamente válidos para a proteção da humanidade em ordem máxima; a legitimação dos direitos humanos, diz ele, não parte de interesses corriqueiros, mas de "interesses de categoria logicamente mais elevada que estejam relacionados com a condição humana" ${ }^{34}$; são, portanto, “interesses antropológicos". E “como as condições consistem em poder ter e buscar interesses em si, pois se referem à capacidade de atuação, elas são de ordem (relativamente) transcendental". 35

Em seguida, Höffe elenca, "sem pretender a completude", alguns direitos sobre os quais não poderia haver desacordo, categorizados em três núcleos centrais ${ }^{36}$ : (i) integridade

\footnotetext{
${ }^{30}$ Marcelo Neves. Justiça e diferença numa sociedade global. In: Jessé Souza (org.). Democracia hoje: novos desafios para a teoria democrática contemporânea. Brasília: UnB, 2001, p. 332.

31 Idem, p. 332. O horizonte teórico é Niklas Luhmann, Sociologia do Direito I. Rio de Janeiro: Tempo Brasileiro, 1983; e Niklas Luhmann. Sozialen Systeme: Grundriß einer allgemeinen Theorie. Frankfurt am Main: Suhrkamp, 1987.

${ }^{32}$ Idem, p. 332-333.

${ }^{33}$ O contexto de sua visão do direito natural como ponto de partida para dimensão política da justiça e do direito pode ser visualizado em Otfried Höffe. Justiça Política - Fundamentação de uma Filosofica Crítica do Direito e do Estado. Trad. Ernildo Stein. Petrópolis/RJ: Vozes, 1991.

34 Otfried Höffe. Estados Nacionais e Direitos Humanos na era da globalização. In: Jean-Christophe Merle e Luiz Moreira (org.). Direito e Legitimidade. São Paulo: Landy, 2003, p. 313.

${ }^{35}$ Idem, p. 313.

${ }^{36}$ Idem, p. 314-318.
} 
do corpo e da vida; (ii) liberdade de opinião e de religião; e (iii) direitos positivos de liberdade, direitos sociais.

O problema reside, exatamente, na determinação de um conteúdo comum para vários ambientes sociais, totalmente díspares entre si, o que constitui, de certo, embaraço às concepções universalistas apregoadas.

O decisivo, na ótica de Höffe, é que, ao se defender tal direito cosmopolita, faz-se necessário, antes de tudo, reconhecer interesses cosmopolitas, com o que se pode perceber, a intransponível dificuldade de um alinhamento pleno de interesses planetários, sem, com isso, desvirtuar certos valores originais de uma determinada sociedade, especialmente aquelas reputadas periféricas.

Nessa direção, a lição do teólogo renegado Hans $\mathrm{Küng}^{37}$ :

(...) por mais diversas que sejam as diferenças nacionais, culturais e religiosas, em toda a parte, trata-se de pessoas humanas e essas pessoas humanas, hoje em dia, sentem-se, através dos modernos sistemas de comunicação, sobretudo do rádio e na televisão, cada vez mais como uma comunidade de destinado sobre esta nossa nave espacial chamada Terra... e aqui se coloca a questão se não pode existir - se não deve existir - um mínimo de valores, normas e atitudes que sejam comuns a todos os homens. Portanto, um consenso ético mínimo.

Retomando a posição de Höffe, a construção desse ideal perpassa pela idéia de um "Estado mundial, proposto ético-juridicamente à humanidade, em função do imperativo universal do direito e da democracia" e que deve ser assentado como uma "república mundial complementar, subsidiária e, ademais, federativa", onde todos possam se considerar "cidadãos do mundo", não em um sentido exclusivo, mas em tal sentido "complementar", ou seja, não se trata de defender um cosmopolitismo inimigo dos Estados individuais... ${ }^{38}$

\footnotetext{
37 Hans Küng. Uma ética global para a política e a economia mundiais. Trad. Carlos Almeida Pereira. Petrópolis: Vozes, 1999, p. 170. O autor suiço foi punido pelo Vaticano em um rumoroso episódio. No dia 18 de dezembro de 1979, a Congregação da Fé do Vaticano cassou a licença de lecionar do Hans Küng, O teólogo arrebatou o ódio do Vaticano ao questionar por várias vezes o dogma da infalibilidade do Papa. Foi professor de teologia na Universidade Pontifícia Gregoriana, em Roma, e em Tubingen, na Alemanha, onde conheceu o Papa Joseph Ratzinger, após terem participado, como jovens teólogos, no Concílio Vaticano II. Em setembro passado, Küng, que preside a Fundação para a Ética Global, manifestou-se muito satisfeito por ter se reencontrado com Bento XVI, em um reunião que considerou "um sinal cheio de esperança". Em declarações ao jornal "Süddeutschen Zeitung", Küng revelou que o encontro resultou de uma troca de correspondência com o Papa, começada pouco tempo depois da eleição de Joseph Raztinger. (Agência Ecclesia [Notícias]. Disponível em: http://www.agencia.ecclesia.pt/. Acesso em: 04 out. 2005).

${ }^{38}$ Otfried Höffe. Visão república mundial: democracia na era da globalização. In: Nythamar Fernandes de Oliveira e Draiton Gonzaga de Souza (orgs.). Justiça e Politica: homenagem a Otfried Höffe. Porto Alegre: EDIPUCRS, 2003, p. 223-224.
} 
Não se focalizará aqui os fundamentos destacados e as objeções comumente refletidas pela Visão República Mundial exposta por Otfried Höffe. A situação-problema afigura-se - e tudo indica que permanecerá naturalmente - conflituosa em qualquer proposta de mínimo consenso ético. Mas importa uma abordagem sistêmica, em que a única possibilidade que se vislumbraria factível é aquela que considera a complexidade solucionável mediante uma fórmula de ponderação, que não adota necessidades e riscos permanentes, outrossim possibilita a (re) inserção de diferentes valores, sem clausuras conceituais, preservando alternativas, como diz Marcelo Neves:

\begin{abstract}
a prevalência dos valores de determinado grupo em um determinado procedimento (eleitoral, legislativo, administrativo ou jurisdicional) do estado democrático de direito justifica-se apenas enquanto é relativa, ou seja, desde que os procedimentos permancem abertos aos valores dos outros grupos, que poderão prevalecer em outra eventualidade procedimental. ${ }^{39}$
\end{abstract}

Por fim, a questão remete à constatação de que as motivações políticas, ideológicas e éticas desse arcabouço em prospecção privilegiam, tão somente, os países centrais - daí porque o próprio Habermas dirige sua formulação de legitimação baseada nos direitos humanos ao paradigma político dos Estados constitucionais democráticos. ${ }^{40}$ Em virtude disso, só se poderia argumentar a premissa kantiana de paz universal valendo-se, sobretudo, da consciência de que o processo constitui apenas uma alternativa, não uma necessidade (Marcelo Neves) e que, sobretudo, deve ser dialógica ou "responsável" (Apel), para não resultar em uma mais etapa da cadeia complexa de intolerância étnica e fundamentalismo religioso, movida por algumas contingências, sem adequada avaliação dos riscos.

A apreciação crítica aqui esboçada não poderia, em hipótese alguma, ser conclusiva, porém assinala, mais uma vez, a percepção de que os atores globais periféricos não devem considerar possível - nem desejável - o alinhamento proposto pelos vários pensadores contemporâneos que acalentam o sonho utópico da paz. Nem os tão verberados interesses cosmopolitas, nem a busca cooperativa pela situação ideal de falas e decisões, calcadas na panacéia democrática são canais factíveis para o consenso ético.

Devem considerar a justiça como componente lingüístico que serve para fundamentar diferentes proporções comunicativas, de acordo com o paradigma em que é assente (liberais, comunitaristas etc).

\footnotetext{
${ }^{39}$ Marcelo Neves. Justiça e diferença numa sociedade global complexa. In: SOUZA, Jessé. (org.). Democracia hoje: novos desafios para a teoria democrática contemporânea. Brasília: UnB, 2001, p. 342.

${ }^{40}$ Jürgen Habermas. Sobre a legitimação baseada nos direitos humanos. Trad. Gisele Guimarães Citadino e Maria Celina Bodin de Moraes. Direito, Estado e sociedade. Rio de Janeiro: PUC-RIO, v. 9, n. 17, ago-dez. 2000, p. 190.
} 
Devem (os atores periféricos) considerar, de modo especial, que a igualdade de condições para todos é atribuída por aqueles que se consideram mais iguais - as culturas centrais (ocidentais).

E devem (todos), sobremaneira, reconhecer que a essência que sustenta obrigações morais e prerrogativas jurídicas é o próprio traço cultural que caracteriza o ser finito que povoa diferentes plagas e que se ocupa de diferentes visões. Nem melhores, nem piores. Diferentes.

\section{Referências}

ADEODATO, João Mauricio. Ética e Retórica - Por uma teoria da dogmática jurídica. São Paulo: Saraiva, 2002.

. La pretensión de universalización del derecho como ambiente ético común In: $E l$ derecho ante la globalización y el terrorismo.Valencia: Tirant lo Blanch, 2004, v.1, p. 99108.

APEL, Karl-Otto. Estudios Éticos. Barcelona: Editorial Alfa, 1986.

Teoría de la verdad y ética del discurso. Barcelona: Paidós-ICE-UAB, 1991.

Plurality of the Good? The Problem of Affirmative Tolerance in a Multicultural Society from an Ethical Point of View. Ratio Juris. Oxford, v. 10, n. 2, p. 199-212, jun. 1997.

Globalización y necesidad de una ética universal. In: CORTINA, Adela e GARCÍAMARZÁ, Domingo. Razón pública y éticas aplicadas. Madrid: Tecnos, 2003, p. 195-196.

ARNAUD, André-Jean. O direito entre Modernidade e Globalização: Lições de Filosofia do Direito e do Estado. Trad. Patrice Charles Wuillaume. Rio de Janeiro: Renovar, 1999.

BARROSO, Luís Roberto. Fundamentos teóricos e filosóficos do novo direito constitucional brasileiro (Pós-modernidade, teoria crítica e pós-positivismo). Revista da Academia Brasileira de Direito Constitucional. Curitiba, a. 1, n. 1, p. 16-59, 2001.

BAUMAN, Zygmunt. Globalização: as conseqüências humanas. Trad. Marcus Penchel. Rio de Janeiro: Zahar Editores, 1999.

BEDIN, Gilmar Antonio. O fenômeno da globalização do mundo e as possibilidades de realização da sociedade atual: é possivel construir uma nova ordem mundial justa e solidária? Estudos Jurídicos. São Leopoldo: Unisinos, v. 36, n. 97, p. 5-34, 2003.

CORTINA, Adela. Ética transnacional e cidade cosmopolita. In: Jean-Christophe Merle e Luiz Moreira (org.). Direito e Legitimidade. São Paulo: Landy, 2003, p. 274-287.

FARIA, José Eduardo (org.). Direito e globalização econômica: implicações e perspectivas. São Paulo: Malheiros, 1998.

GOMES, Alexandre Travessoni. Ética, direito e paz perpétua. In: Jean-Christophe Merle e Luiz Moreira (org.). Direito e Legitimidade. São Paulo: Landy, 2003, p. 298-308.

HÄBERLE, Peter. El Estado Constitucional Europeo. Trad. Francisco Balaguer Callejón. Cuadernos constitucionales. México, n. 2, p. 87-104, jan-jun. 2000. 
HABERMAS, Jürgen. Consciência Moral e Agir Comunicativo. Trad. Guido A. de Almeida. Rio de Janeiro: Tempo Brasileiro, 1989.

Direito e democracia - Entre facticidade e validade. Trad. Flávio Beno Siebeneichler. Rio de Janeiro: Tempo Brasileiro, 1997, t. I.

Sobre a legitimação baseada nos direitos humanos. Trad. Gisele Guimarães Citadino e Maria Celina Bodin de Moraes. Direito, Estado e sociedade. Rio de Janeiro: PUC-RIO, v. 9, n. 17, p. 190-208, ago-dez. 2000.

HOBSBAWN, Eric. A Era dos Extremos: O Breve Século XX - 1914-1991. São Paulo: Companhia das Letras, 1995.

HÖFFE, Otfried. Justiça Política - Fundamentação de uma Filosofica Crítica do Direito e do Estado. Trad. Ernildo Stein. Petrópolis/RJ: Vozes, 1991.

. Estados Nacionais e Direitos Humanos na era da globalização. In: MERLE, JeanChristophe; e MOREIRA, Luiz (org.). Direito e Legitimidade. São Paulo: Landy, 2003.

. Visão república mundial: democracia na era da globalização. In: OLIVEIRA, Nythamar Fernandes de e SOUZA, Draiton Gonzaga de (orgs.). Justiça e Política: homenagem a Otfried Höffe. Porto Alegre: EDIPUCRS, 2003, p. 205-224.

KÜNG, Hans. Uma ética global para a política e a economia mundiais. Trad. Carlos Almeida Pereira. Petrópolis: Vozes, 1999.

OLIVEIRA, Manfredo Araújo de. Desafios Éticos da Globalização. São Paulo: Paulinas, 2001.

NEVES, Marcelo. Justiça e diferença numa sociedade global complexa. In: SOUZA, Jessé. (org.). Democracia hoje: novos desafios para a teoria democrática contemporânea. Brasília: UnB, 2001, p. 329-363.

NINO, Carlos Santiago. Ética y derechos humanos - un ensayo de fundamentación. 2. ed. Buenos Aires: Astrea, 1989.

RABENHORST, Eduardo. Direitos humanos e globalização contra-hegemônica: notas para o debate. In: Lyra, Rubens Pinto (org.). Direitos humanos: os desafios do século XXI - uma abordagem interdisciplinar. Brasília: Brasília Jurídica, 2002, p. 17-24.

SALGADO, Joaquim Carlos. A idéia de justiça em Kant. 2. ed. Belo Horizonte, 1995.

ZOLO, Danilo. Positive Tolerance: An Ethical Oxymoron. Ratio Juris. Oxford, v. 10, n. 2, p. 241-251, jun. 1997. 